\title{
Molecular markers of resistance to sulphadoxine-pyrimethamine one year after implementation of intermittent preventive treatment of malaria in infants in Mali
}

Alassane Dicko ${ }^{1,2^{*}}$, Issaka Sagara', Abdoulaye A Djimdé1, Sidy O Touré ${ }^{1}$, Mariam Traore ${ }^{1}$, Souleymane Dama ${ }^{1}$, Abdoulbaki I Diallo', Amadou Barry', Mohamed Dicko', Oumar M Coulibaly ${ }^{3}$, Christophe Rogier ${ }^{4}$, Alexandra de Sousa ${ }^{5}$, Ogobara K Doumbo ${ }^{1}$

\begin{abstract}
Background: Intermittent preventive treatment in infants (IPTi) with sulphadoxine-pyrimethamine (SP) given during routine vaccinations is efficacious in preventing malaria disease and shows no interaction with the vaccines. However, there is a fear that IPTi may result in a rapid increase of parasite resistance to SP.

Methods: To evaluate the impact of IPTi on SP-resistance point mutations, the 22 health sub-districts in the district of Kolokani, Mali, were randomized in a 1:1 ratio and starting in December 2006, IPTi with SP was implemented in 11 health sub-districts (intervention zone), while the other 11 health sub-districts served as the control (nonintervention zone). Blood smears and blood dots on filter paper were obtained from children aged 0-5 years, randomly selected in each of heath sub-districts during two cross-sectional surveys. The first survey was conducted in May 2007 before the start of the transmission season to collect baseline prevalence of the molecular markers of resistance to SP and the second in December 2007 after the end of the transmission season and one year after implementation of IPTi. A total of 427 and 923 randomly selected blood samples from the first and second surveys respectively were analysed by PCR for dhfr and dhps mutations.
\end{abstract}

Results: Each of the three dhfr mutations at codons 51, 59 and 108 was present in 35\% and 57\% of the samples during the two surveys with no significant differences between the two zones. Dhps mutations at codons 437 and 540 were present respectively in about $20 \%$ and $1 \%$ of the children during the two surveys in both zones at similar proportion. The prevalence of quadruple mutants (triple dhfr-mutants + dhps-437G) associated with in-vivo resistance to SP in Mali after one year implementation of IPTi was also similar between the two zones (11.6\% versus $11.2 \%, p=0.90)$ and to those obtained at baseline survey (10.3\% versus $8.1 \%)$.

Conclusion: This study shows no increase in the frequency of molecular markers of SP resistance in areas where IPTi with SP was implemented for one year.

\footnotetext{
* Correspondence: adicko@mrtcbko.org

${ }^{1}$ Malaria Research and Training Center, Department of Epidemiology of

Parasitic Diseases, Faculty of Medicine Pharmacy and Dentistry, University of Bamako, PO Box 1805 Bamako, Mali
} 


\section{Background}

Malaria remains a major cause of morbidity and mortality with an estimate of 881,000 deaths per year of which 91\% occur in sub-Saharan Africa, mainly in infants and children under five years of age [1]. In the absence of a vaccine, simple and effective control strategies are urgently needed to reduce the malaria burden in subSaharan Africa. Several randomized controlled trials have demonstrated that Intermittent Preventive Treatment of malaria in infants (IPTi) with sulphadoxine-pyrimethamine (SP) given during routine vaccinations of the Expanded Programme of Immunization (EPI) at approximately two, three and nine months of age, result in a reduction of the incidence of clinical malaria by 22 to $59 \%[2-8]$, without showing interactions with EPI vaccines $[2,4,9]$. Although the efficacy and safety as well as the lack of interaction with EPI vaccines of IPTi in various endemic areas were well established [10-12], there have been concerns regarding the possibility that this strategy may cause an increase of Plasmodium falciparum resistance to SP, jeopardizing the use of SP not only for the prevention of malaria in infants, but also in pregnant women [13-15], an intervention widely adopted in many countries in sub-Saharan Africa. SP is known to rapidly select for mutant SP-resistant parasites [16-19], especially when given in prophylaxis, despite the reassuring predictions from mathematical modeling $[13,20]$. A report on the impact of IPTi with SP on the resistance of $P$. falciparum to SP in Mozambican children found no difference in the frequencies of $d h f r$ and dhps mutations in children with a clinical malaria episode two months after the third dose of IPTi [21]. However, this study was conducted in the context of a placebo-controlled randomized trial with a limited number $(n=174)$ of samples. An evaluation in a context of large-scale implementation was needed to adequately address the impact of IPTi on SP drug resistance. This study evaluated the impact of IPTi on the selection SPresistant $d h f r$ and dhps mutations in P. falciparum after 12 months of implementation of IPTi in the district of Kolokani, Mali, where UNICEF pilot implementation of IPTi with SP was undertaken as part of a large operational research study in six African malaria endemic countries.

\section{Methods}

\section{Study site}

The study was conducted in the district of Kolokani, Mali. The district of Kolokani is an administrative subdivision of the region of Koulikoro. The town of Kolokani is located approximately $140 \mathrm{~km}$ north of Bamako. The district covers $14,380 \mathrm{~km}^{2}$ and is divided into 22 health sub-districts. Each health sub-district is composed of several villages and has a health care center under the responsibility of a physician or chief-nurse and is staffed with at least two or three midwives and vaccinators. Three physicians ensure the coordination of health activities at the district level. The total population was 214,509 inhabitants. The children under one year of age represent about $4 \%$ of the total population. Malaria transmission is seasonal (July to November) with parasite prevalence in children $0-5$ years of $45 \%$ at the end of the no-transmission season and above $70 \%$ at the end of the transmission season. First-line treatment of uncomplicated malaria was artesunate-amodiaquine or artemether-lumefantrine. Quinine was recommended for the treatment of severe malaria and SP was recommended prophylaxis for pregnant women.

\section{Study participants and design}

The study was a cluster-randomized trial. Twenty-two health sub-districts were randomized into two groups in a 1:1 ratio and IPTi was implemented in 11 health subdistricts (intervention zone) while the other 11 health sub-districts served as the control (non-intervention zone). The implementation of IPTi started in December 2006 and consisted of the administration of $1 / 2$ tablet of SP alongside the DTP2, DTP3 and Measles routine immunizations. Afridoxine ${ }^{\bullet}$ (manufactured by Fourrts Laboratories Pvt. Ltd, Tamil Nadu, India), a breakable and dispersible form of SP was used after quality controls at the Laboratoire National de Santé in Bamako, Mali. Two cross-sectional surveys were performed. The first survey was performed in May 2007 a few months after the start of the IPTi-implementation, but before the start of the transmission season to collect baseline prevalence of the molecular markers of SP resistance. The second cross-sectional survey was conducted after one year of implementation in December 2007 after the end of the transmission season, to assess the impact of IPTi on the selection of SP-resistant $d h f r$ and dhps mutations in $P$. falciparum. Children aged 0-5 years randomly selected in each of the health sub-districts were screened for malaria parasitaemia using thick smears obtained by finger pricking. Filter paper blood dots were also collected at the same time for the analysis of SP resistance molecular markers.

\section{Laboratory methods}

Thick smears were Giemsa-stained and examined by microscopy. Parasite density was determined by counting parasites against 300 leucocytes using a conversion factor of 25, based on an assumed leukocyte count of $7,500 / \mu$ l. Filter papers samples were air-dried and stored at room temperature in labeled individual envelopes. Preliminary genotyping of one hundred samples demonstrated that samples with a parasitaemia less than 500 parasites $/ \mu$ lid not consistently yield PCR product. 
Therefore, only filter paper samples from children with $P$. falciparum mono-infection parasitaemia greater or equal to 500 asexual stages per $\mu$ l of blood were analysed by PCR for dhfr and dhps point mutations. Because of a higher than expected number $P$. falciparum mono-infection positive samples, 427 samples of the baseline survey and 923 samples of end of one year implementation survey were randomly selected and tested by PCR. Of the 427 baseline survey samples, 274 samples (150 in the intervention zone and 124 in the non-intervention zone) were successfully genotyped for all three $d h f r$ and two dhps mutations, while the remaining were successfully tested for one, two, three or four mutations. Of the 923 randomly selected samples of end of one-year implementation survey, 742 samples (379 in the intervention zone and 363 in the non-intervention zone) were successfully genotyped for all three $d h f r$ and two dhps mutations, and the remaining for one, two, three or four mutations.

A simple DNA extraction method for filter paper strips was used [22]. Briefly, approximately $1 \times 2 \mathrm{~mm}$ piece of blood-soaked filter paper was placed in $50 \mu \mathrm{l}$ of methanol for $15 \mathrm{~min}$. The methanol was poured off and the paper heated at $95-100^{\circ} \mathrm{C}$ in $50 \mu \mathrm{l}$ of water for 10 minutes. Five microliters of the resulting solution was used as PCR template for the first round of the Nested PCR. One microliter of the product of the first PCR was amplified in the second round of PCR. Samples that failed to yield PCR amplification with the methanol method were re-extracted using an alternative chelexbased method [23]. Dhfr and dhps genotypes were determined using nested mutation-specific PCR and/or PCRRFLP according to published methods [16,23]. Dhfr mutations at codons 51, 59 and 108 and dhps mutations at codons 437 and 540 were analysed. One third of the PCR gels were examined by a senior scientist external to the study. The conformity of the gels with standard criteria for PCR gel validation and the fidelity of the transcription of lab notebook (source documents) with electronic files were checked. Error cases were corrected and PCR analyses repeated as needed.

\section{Study endpoints}

The primary endpoint was the frequency of quadruple mutant of molecular markers (dhfr 51, 59 and 108 and dhps 437) after one year of IPTi implementation. Secondary endpoints were the frequencies of single mutations as well as the triple mutants $(d h f r 51+59+108)$ determined by PCR at the end of one year of implementation and frequencies of these individual and multiples $d h f r$ and dhps mutations at baseline. The frequency of a particular mutant was calculated as the proportion of the specific mutant samples among the total number of samples successfully analysed for this mutation. Similarly, the frequencies of triple, quadruple and quintuple mutants were determined as the proportion of subjects with the three, four and five mutations among the total numbers of samples tested for the each.

\section{Sample size}

Assuming a proportion of the primary endpoint (quadruple mutants, dhfr 51, 59 and 108 and dhps 437) of 8\% in control zone and $14 \%$ in IPTi intervention zone, one side p-value 0.025 , a power of $80 \%$, and inter class correlation using 0.01 , a sample size of 380 children with positive parasitaemia in each group with a minimum of 22 subjects and average of 35 subjects per cluster were needed. Assuming a prevalence of $P$. falciparum parasitaemia of $35 \%$ and about $10 \%$ lost or unsuccessful samples, about 110 subjects were need to be screened per cluster resulting in a total of 2,420 children for the two arms.

\section{Statistical analysis}

Cases of mixed infection (wild type and mutant) were categorized as mutant throughout the analysis. Prevalence of single mutations as well as the triple mutant $($ dhfr $51+59+108)$ and quadruple mutant (triple mutant + dhps 437) genotypes were determined and compared between the IPTi implementation and control zones with 95\% confidence intervals around the odds ratios adjusted for non-independence within health subdistricts using cluster option in Stata (version 9, Houston Texas USA). Proportions of categorical variables were compared using Pearson's Chi square test. Student $t$ test was used for the comparison of mean ages and Mann-Whitney test for the comparison of parasite densities between the two zones.

\section{Ethical considerations}

Ethical clearance was obtained from the Ethical Committee of the Faculty of Medicine Pharmacy and Dentistry of the University of Bamako, Mali, and written informed consent from a parent or legal guardian was obtained prior to the enrollment of the child in the survey.

\section{Results}

Prevalence of $d h f r$ and dhps mutations at baseline survey A total of 2,437 subjects were screened (1,213 in the intervention zone and 1,224 in the non-intervention zone). Among these, 1,157 subjects (573 in the intervention zone and 584 in the non-intervention zone) had $P$. falciparum parasitaemia and 858 (429 in each zone) with parasitaemia equal or above $500 / \mu$ l were selected. Characteristics of subjects enrolled are presented in Table 1. There were no significant differences between the two groups in terms of age, parasite prevalence, parasite density, and prevalence of parasitaemia equal or above 500/ $\mathrm{\mu l}$.

Prevalence of individual mutations, triple and quadruple mutations in intervention and non-intervention 
Table 1 Characteristics of subjects enrolled in the IPTi intervention and non-intervention zone in Kolokani in May 2007.

\begin{tabular}{|c|c|c|c|}
\hline & No IPTi & IPTi & $p$ \\
\hline Number screened & 1224 & 1213 & \\
\hline Mean age (months) & 34.1 & 32.9 & 0.15 \\
\hline Gender (Male) (\%) & 53.4 & 50.9 & 0.21 \\
\hline Parasite prevalence (\%) & 47.7 & 47.2 & 0.82 \\
\hline $\begin{array}{l}\text { Median parasitaemia (per } \\
\mu l)\end{array}$ & 950 & 1275 & 0.44 \\
\hline $\begin{array}{l}\text { Prevalence of parasitaemia } \\
\geq 500 / \mu \mathrm{l}(\%)\end{array}$ & 35.1 & 35.2 & 0.87 \\
\hline
\end{tabular}

zones are presented in Table 2. Prevalence of individual $d h f r$ and $d h p s$ mutations and triple $d h f r$ mutation were similar between the intervention and non-intervention zones. The quadruple mutation was present in $9.2 \%$ of all the samples with similar frequency in the two zones (10.3\% in the intervention zone and $8.1 \%$ in the nonintervention zone).

Prevalence of dhfr and dhps mutations after one year of IPTi implementation

A total of 2,453 subjects were screened $(1,227$ in the intervention zone and 1,226 in the non-intervention zone). Among these, 1,693 (855 in the intervention zone and 838 in the non-intervention zone) had $P$. falciparum parasitaemia and 1,490 (735 in the intervention zone and 755 in the non-intervention zone) had $P$. falciparum parasitaemia equal or above $500 / \mu$ l. Characteristics of children sampled in the two zones are presented in Table 3. There were no significant differences between the two groups in terms of age, parasite prevalence, parasite density and prevalence of parasitaemia equal or above $500 / \mu \mathrm{l}$.

Prevalence of individual $d h f r$ and $d h p s$ mutations as well as multiple mutations ( $d h f r$ triple mutation and quadruple mutation (triple + dhps 437)) are presented in Table 4. There were no significant differences in the frequency of individual mutations between intervention and non-intervention zones. About half of the children harboured one of three $d h f r$ mutations in both the intervention and non-intervention zones with a frequency of the triple $d h f r$ mutation of $38.5 \%$ in the intervention zone compared to $44.8 \%$ in the control zone. About $20 \%$ of the children with parasitaemia in each zone were positive for parasites with the mutation 437 on dhps while only about $1 \%$ harboured parasites with the dhps 540 mutation. Similar patterns were found when the analysis was done by age categories for 2-24 months and 25-60 months.

The prevalence of the quadruple mutants was also similar between the two zones: $11.6 \%$ in the intervention zone versus $11.2 \%$ in the control zone, odd ratio $=1.04$ (95\% CI 0.51-2.12) $\mathrm{p}=0.90$ (Table 4). When the data were analysed by age categories, similar frequencies of quadruple mutants were found in the two zones in children aged 2-24 months; $9.9 \%(14 / 142)$ in the intervention group versus $8.2 \%(12 / 147)$ in the control group ( $p$ $=0.62$ ). The corresponding figures in children aged 2560 months were $12.9 \%(29 / 236)$ in the intervention group and $13.2 \%(29 / 219)$ in the control group ( $\mathrm{p}=$ $0.76)$.

Three of the overall 742 samples $(0.8 \%)$ successfully genotyped for all three $d h f r$ and two dhps, harboured quintuple mutants; all three in the non-intervention zone, with one in the younger age group (less or equal to 24 months) and the other two in the older age group (25-60 months).

\section{Discussion}

This study showed no difference between intervention and non-intervention zones in the frequency of individual mutants in the $d h f r$ and dhps genes, as well as in the triple $d h f r$ and quadruple $d h f r$ dhps mutants, suggesting that the implementation of IPTi with SP for one year does not result in an increase in the frequency of these molecular markers at the community level. This is consistent with the predictions using mathematical modelling that have indicated that IPTi is unlikely to appreciably shorten the useful life of the drug used [20],

Table 2 Prevalence of molecular markers associated with P. falciparum resistance to SP in IPTi intervention and nonintervention zone in Kolokani at baseline in May 2007.

\begin{tabular}{|c|c|c|c|c|c|}
\hline \multirow[b]{2}{*}{ Molecular Markers } & \multicolumn{2}{|c|}{ No IPTi } & \multicolumn{2}{|c|}{ IPTi } & \multirow[t]{2}{*}{$p$} \\
\hline & $\mathrm{n}$ & Prevalence & $\mathrm{n}$ & Prevalence & \\
\hline DHPS 437 & 333 & $20.1 \%$ & 315 & $17.5 \%$ & 0.39 \\
\hline DHPS 540 & 265 & $0.4 \%$ & 313 & $1.6 \%$ & 0.22 \\
\hline DHFR 51 & 209 & $35.4 \%$ & 216 & $38.4 \%$ & 0.52 \\
\hline DHFR 59 & 220 & $48.2 \%$ & 206 & $47.6 \%$ & 0.90 \\
\hline DHFR 108 & 223 & $43.0 \%$ & 242 & $38.0 \%$ & 0.27 \\
\hline Triple DHFR mutation & 179 & $34.6 \%$ & 184 & $35.8 \%$ & 0.81 \\
\hline Quadruple mutation & 161 & $8.1 \%$ & 174 & $10.3 \%$ & 0.47 \\
\hline
\end{tabular}


Table 3 Characteristics of subjects enrolled in the IPTi intervention and non-intervention zone in Kolokani in December 2007 after one year of implementation.

\begin{tabular}{|c|c|c|c|}
\hline & No IPTi & IPTi & $p$ \\
\hline Number screened & 1226 & 1227 & \\
\hline Mean age (months) & 32.9 & 33.0 & 0.96 \\
\hline Gender (Male) (\%) & 51.3 & 50.3 & 0.63 \\
\hline Parasite prevalence (\%) & 71.5 & 73.3 & 0.32 \\
\hline Median parasitaemia (per $\mu \mathrm{l}$ ) & 3325 & 3850 & 0.06 \\
\hline $\begin{array}{l}\text { Prevalence of parasitaemia } \geq \\
500 / \mu l(\%)\end{array}$ & 62.7 & 64.8 & 0.31 \\
\hline
\end{tabular}

or to significantly impact on the spread of highly resistant parasites in areas where partial resistance is already established [13] as it is the case in Mali and in many countries in sub-Saharan Africa. A small scale placebocontrolled randomized trial of IPTi with SP in Mozambican children [21] found no difference in the frequency of $d h f r$ and dhps mutations during the episodes of clinical malaria that occurred two months after the last dose of IPTi. Another study [24] found a higher frequency of infections exhibiting four mutations in $d h f r$ and dhps in children of nine months of age, after a single dose of SP compared to those in the control group, but no difference in the rate of infections with isolates with less than four mutations between the two groups. Other small scale placebo-control randomized studies of IPT in children (IPTc) during a highly seasonal malaria transmission season did not find differences in the frequency of dhfr and dhps mutations [25] or in vivo response to SP [26] between those who received IPT with SP versus those who did not. Similar frequency of the $d h f r$ triple mutant among antennal care attendees of early gestation who had not received IPT and delivering women who had received IPT with SP in pregnancy (IPTp) was reported in a study in Ghana [18]. As estimated in mathematical models, the drug pressure resulting from IPTi may be relatively small [20] and there is no evidence that IPT will lead to increased resistance to SP that could jeopardize the use of the strategy in many countries in sub-Saharan Africa. However, this study has assessed the impact of IPTi on molecular markers of SP resistance after only one year of implementation, and continuous monitoring of resistance to SP (both molecular and in vivo) would be warranted once IPT is to be implemented as policy for longer periods of time. Possible limitations of this study include i) potential bias due to the difference in the spread of resistance between this study target population (children between 0-5 years of age) and the IPTi target population (children less than one year of age), however the sub-groups analysis did not shown any difference between the two zones in the children 2-24 months at the time of the second crosssectional survey, targeted by the intervention and ii) the possibility of cross-contamination between intervention and non-intervention zones. However, the use of IPTi in non-intervention zones is unlikely to bias our results as only a very small proportion (less than $1 \%$ ) of children 0-23 months had received IPTi in the non-intervention zone, and a high coverage of IPTi $(>90 \%$ based on health records) was achieved in the intervention zone. Furthermore, the frequency of quadruple mutants at baseline was $10.3 \%$ compared to $11.6 \%$ at the end of first year of intervention and $8.1 \%$ compared to $11.2 \%$ in the control group. Rapid selection under drug pressure

Table 4 Prevalence of molecular markers associated with $P$. falciparum resistance to SP in IPTi intervention and nonintervention zone in Kolokani in December 2007 after one year of implementation.

\begin{tabular}{|c|c|c|c|c|c|c|c|}
\hline \multirow[b]{2}{*}{ Molecular Markers } & \multicolumn{2}{|c|}{ No IPTi } & \multicolumn{2}{|c|}{ IPTi } & \multirow[t]{2}{*}{ OR } & \multirow[t]{2}{*}{$95 \% \mathrm{Cl}$} & \multirow[t]{2}{*}{$p$} \\
\hline & $n$ & $\begin{array}{c}\text { Prevalence } \\
(95 \% \mathrm{Cl})\end{array}$ & $n$ & $\begin{array}{l}\text { Prevalence } \\
(95 \% \mathrm{CI})\end{array}$ & & & \\
\hline DHPS 437 & 432 & $\begin{array}{c}19.4 \% \\
(15.1-24.6)\end{array}$ & 479 & $\begin{array}{c}21.7 \% \\
(17.4-26.7)\end{array}$ & 1.15 & $0.59-2.24$ & 0.68 \\
\hline DHPS 540 & 428 & $\begin{array}{c}0.9 \% \\
(0.2-3.1)\end{array}$ & 474 & $\begin{array}{c}1.0 \% \\
(0.3-3.1)\end{array}$ & 1.13 & $0.16-7.99$ & 0.90 \\
\hline DHFR 51 & 379 & $\begin{array}{c}56.5 \% \\
(50.1-62.6)\end{array}$ & 402 & $\begin{array}{c}51.0 \% \\
(44.9-57.1)\end{array}$ & 0.80 & $0.52-1.23$ & 0.32 \\
\hline DHFR 59 & 376 & $\begin{array}{c}55.3 \% \\
(48.9-61.5)\end{array}$ & 402 & $\begin{array}{c}51.0 \% \\
(44.9-57.1)\end{array}$ & 0.84 & $0.50-1.40$ & 0.51 \\
\hline DHFR 108 & 375 & $\begin{array}{c}56.8 \% \\
(50.4-63.0)\end{array}$ & 392 & $\begin{array}{c}47.7 \% \\
(41.5-53.9)\end{array}$ & 0.69 & $0.47-1.03$ & 0.07 \\
\hline $\begin{array}{l}\text { Triple DHFR mutation } \\
\text { (DHFR 51, } 59 \text { and 108) }\end{array}$ & 368 & $\begin{array}{c}44.8 \% \\
(38.5-51.3)\end{array}$ & 384 & $\begin{array}{c}38.5 \% \\
(32.6-44.8)\end{array}$ & 0.77 & $0.50-1.19$ & 0.24 \\
\hline $\begin{array}{l}\text { Quadruple mutation } \\
\text { (DHFR 51, } 59 \text { and } 108 \\
+ \text { DHPS 437) }\end{array}$ & 367 & $\begin{array}{c}11.2 \% \\
(7.6-16.0)\end{array}$ & 379 & $\begin{array}{c}11.6 \% \\
(8.1-16.4)\end{array}$ & 1.04 & $0.51-2.12$ & 0.90 \\
\hline
\end{tabular}


of pre-existent resistant strains at the community level has been reported [27]. However, in the absence of structured $P$. falciparum populations, the flow of parasites between areas that are very close could have diluted P. falciparum populations that were selected under SP pressure in the intervention zones by unselected $P$. falciparum populations coming from nonintervention zones [28]. The use of threshold parasitaemia equal or above $500 / \mu$ lis unlikely to bias our results since the prevalence of parasitaemia above this threshold was similar between the two zones, and it is unlikely that mutants parasite were more prevalent below this threshold in one zone compared to other.

In line with other studies in Mali and countries in West Africa [29-32], this study shows relatively high levels of individual $d h f r$ mutations in the study area with half of the parasitemic children harbouring mutant genotypes and a prevalence of triple mutations of $44.5 \%$. This may reflect the long history of usage of sulpha drugs including SP across the countries. Although the $d h f r$ triple mutation was prevalent in 34.6 to $44.8 \%$ of infections, it is well established that this genotype does not correlate with in vivo SP failure in West Africa [31-33]. The quadruple mutation genotype most associated with in vivo SP failure in Mali (our unpublished data) and in Ghana [33] was similar between the two zones and present in about $11 \%$ of infections in overall at the end of one year of implementation. This is also consistent with rates for this genotype found by us in various parts of Mali and by others in the West African sub-region $[31,34,35]$. Similar to other reports from the sub-region, the dhps $540 \mathrm{E}$ was very rare in this study $[31,33]$. However, here are reported the first cases of dhps 540E found in Mali.

In conclusion, this study shows low prevalence of quadruple mutants (triple dhfr mutants + dhps 437G) associated with in vivo resistance to SP in Mali and no evidence of increased frequency of molecular markers of SP resistance in areas where IPTi was implemented for one year.

\footnotetext{
Acknowledgements

We are very grateful to the children who participate into the study; their parents and the staff of district and community health Centers of Kokokani as well as the Regional Health Office of Koulikoro, Mali. We thank Dr Andrea Egan and members of IPTi consortium for their helpful comments and critical reading of the manuscript. Special thanks to Dr. Alpha Telli Diallo and all the staff of the UNICEF office in Bamako for their great support. The study was funded by the Bill and Melinda Gates Foundation to UNICEF in support of the IPTi Consortium http://www.ipti-malaria.org.
}

\section{Author details}

${ }^{1}$ Malaria Research and Training Center, Department of Epidemiology of Parasitic Diseases, Faculty of Medicine Pharmacy and Dentistry, University of Bamako, PO Box 1805 Bamako, Mali. Department of Public Health, Faculty of Medicine Pharmacy and Dentistry, University of Bamako, PO Box 1805 Bamako, Mali. ${ }^{3}$ Centre de santé de référence de Kolokani, Région de
Koulikoro, Mali. ${ }^{4}$ Institut de Recherche Biomédicale des Armées IRBA - exIMTSSA UMR6236-URMITE, Allée du Médecin colonel Jamot, Parc du Pharo, BP60109, 13262 Marseille cedex 07, France. ${ }^{5}$ UNICEF-Head Quarters, 3 UN Plaza, New York, NY 10017, USA.

\section{Authors' contributions}

AD was the principal investigator of the study. He contributed to the study design, oversaw the study conduct, the data collection and contributed to the data analysis and interpretation. IS contributed to the study design and conducted the data collection. AAD contributed to the study design and oversaw the molecular analysis of the samples and interpretation of the data. Data collection in the field was done by ST, MT, SD, AID, AB, MD. OMC contributed to the study conduct and data collection. CR contributed to the study design and data analysis. AS contributed to the study design. OKD contributed to the design of the study and overseeing the data collection, analysis and interpretation. The manuscript was drafted by AD and all the authors contributed to revision and approved the final version.

\section{Competing interests}

The authors declare that they have no competing interests.

Received: 14 September 2009

Accepted: 10 January 2010 Published: 10 January 2010

\section{References}

1. WHO, World Malaria Report: 2008http://www.who.int/malaria/wmr2008/ malaria2008.pdf.

2. Schellenberg D, Menendez C, Kahigwa E, Aponte J, Vidal J, Tanner M, Mshinda $\mathrm{H}$, Alonso $\mathrm{P}$ : Intermittent treatment for malaria and anaemia control at time of routine vaccinations in Tanzanian infants: a randomised, placebo-controlled trial. Lancet 2001, 357:1471-1477.

3. Chandramohan D, Owusu-Agyei S, Carneiro I, Awine T, Amponsa-Achiano K, Mensah N, Jaffar S, Baiden R, Hodgson A, Binka F, Greenwood B: Cluster randomised trial of intermittent preventive treatment for malaria in infants in area of high, seasonal transmission in Ghana. BMJ 2005, 331:727-733.

4. Macete $E$, Aide $P$, Aponte JJ, Sanz S, Mandomando I, Espasa M, Sigauque B, Dobaño C, Mabunda S, DgeDge M, Alonso P, Menendez C: Intermittent preventive treatment for malaria control administered at the time of routine vaccinations in Mozambican infants: a randomized, placebocontrolled trial. J Infect Dis 2006, 194:276-285.

5. Kobbe R, Kreuzberg C, Adjei S, Thompson B, Langefeld I, Thompson PA, Abruquah HH, Kreuels B, Ayim M, Busch W, Marks F, Amoah K, Opoku E, Meyer CG, Adjei O, May J: A randomized controlled trial of extended intermittent preventive antimalarial treatment in infants. Clin Infect Dis 2007, 45:6-25.

6. Mockenhaupt FP, Reither K, Zanger P, Roepcke F, Danquah I, Saad E, Ziniel P, Dzisi SY, Frempong M, Agana-Nsiire P, Amoo-Sakyi F, Otchwemah R, Cramer JP, Anemana SD, Dietz E, Bienzle U: Intermittent preventive treatment in infants as a means of malaria control: a randomized, double-blind, placebo-controlled trial in Northern Ghana. Antimicrob Agents Chemother 2007, 51:3273-3281.

7. Grobusch MP, Lell B, Schwarz NG, Gabor J, Dornemann J, Potschke M, Oyakhirome S, Kiessling GC, Necek M, Langin MU, Klein Klouwenberg P, Klopfer A, Naumann B, Altun H, Agnandji ST, Goesch J, Decker M, Salazar CL, Supan C, Kombila DU, Borchert L, Koster KB, Pongratz P, Adegnika AA, Glasenapp I, Issifou S, Kremsner PG: Intermittent preventive treatment against malaria in infants in Gabon-a randomized, doubleblind, placebo-controlled trial. J Infect Dis 2007, 196:1595-1602.

8. Grobusch MP, Egan A, Gosling RD, Newman RD: Intermittent preventive therapy for malaria: progress and future directions. Curr Opin Infect Dis 2007, 20:613-620.

9. WHO, Interim report on IPTi with SP: WHO Advisory Committee on Serological responses to EPI vaccines in infants receiving IPTi. (Internal Report) 2006.

10. ter Kuile FO, Steketee RW: Intermittent preventive treatment in infantsadjusting expectations and seeing opportunity. J Infect Dis 2006, 194:269272 .

11. Institute of Medicine: Assessment of the role of intermittent preventive treatment for malaria in infants. Letter Report http://www.iom.edu/Reports/ 
2008/Assessment-of-the-Role-of-Intermittent-Preventive-Treatment-forMalaria-in-Infants-Letter-Report.aspx.

12. Aponte JJ, Schellenberg D, Egan A, Breckenridge A, Carneiro I, Critchley J, Danquah I, Dodoo A, Kobbe R, Lell B, May J, Premji Z, Sanz S, Sevene E, Soulaymani-Becheikh R, Winstanley P, Adjei S, Anemana S, Chandramohan D, Issifou S, Mockenhaupt F, Owusu-Agyei S, Greenwood B, Grobusch MP, Kremsner PG, Macete E, Mshinda H, Newman RD, Slutsker L, Tanner M, Alonso P, Menendez C: Efficacy and safety of intermittent preventive treatment with sulfadoxine-pyrimethamine for malaria in African infants: a pooled analysis of six randomised, placebo-controlled trials. Lancet 2009, 374:1533-1542.

13. O'Meara WP, Smith DL, McKenzie FE: Potential impact of intermittent preventive treatment (IPT) on spread of drug-resistant malaria. PLoS Med 2006, 3:e141.

14. Report of the Technical Expert Group (TEG): Meeting on Intermittent Preventive Therapy in Infancy (IPTi), Geneva, 8-10 October 2007 http://malaria. who.int/docs/IPTi/TEGConsultIPTiOct2007Report.pdf.

15. WHO IPTi Technical Expert Group: Intermittent preventive antimalarial treatment in infancy. Lancet 2008, 372:1383-1384.

16. Doumbo OK, Kayentao K, Djimde A, Cortese JF, Diourte Y, Konare A, Kublin JG, Plowe CV: Rapid selection of Plasmodium falciparum dihydrofolate reductase mutants by pyrimethamine prophylaxis. $J$ Infect Dis 2000, 182:993-996.

17. Sendagire $H$, Kaddumukasa M, Ndagire D, Aguttu C, Nassejje M, Pettersson M, Swedberg G, Kironde F: Rapid increase in resistance of Plasmodium falciparum to chloroquine-Fansidar in Uganda and the potential of amodiaquine-Fansidar as a better alternative. Acta Trop 2005 95:172-182.

18. Mockenhaupt FP, Bedu-Addo G, Eggelte TA, Hommerich L, Holmberg V von Oertzen C, Bienzle U: Rapid increase in the prevalence of sulfadoxine-pyrimethamine resistance among Plasmodium falciparum isolated from pregnant women in Ghana. J Infect Dis 2008, 198:1545-1549.

19. Enosse S, Magnussen P, Abacassamo F, Gómez-Olivé X, Rønn AM, Thompson R, Alifrangis M: Rapid increase of Plasmodium falciparum dhfr/ dhps resistant haplotypes, after the adoption of sulphadoxinepyrimethamine as first-line treatment in 2002, in southern Mozambique. Malar J 2008, 7:115.

20. Alexander N, Sutherland C, Roper C, Cissé B, Schellenberg D: Modelling the impact of intermittent preventive treatment for malaria on selection pressure for drug resistance. Malar J 2007, 6:9.

21. Mayor A, Serra-Casas E, Sanz S, Aponte JJ, Macete E, Mandomando I, Puyol L, Berzosa P, Dobaño C, Aide P, Sacarlal J, Benito A, Alonso P, Menéndez C: Molecular markers of resistance to sulfadoxinepyrimethamine during intermittent preventive treatment for malaria in Mozambican infants. J Infect Dis 2008, 197:1737-1742.

22. Djimdé A, Doumbo OK, Cortese JF, Kayentao K, Doumbo S, Diourté $Y$, Dicko A, Su XZ, Nomura T, Fidock DA, Wellems TE, Plowe CV, Coulibaly D: A molecular marker for chloroquine-resistant falciparum malaria. NEJM 2001, 344:257-263.

23. Plowe CV, Djimde A, Bouare M, Doumbo O, Wellems TE: Pyrimethamine and proguanil resistance-conferring mutations in Plasmodium falciparum dihydrofolate reductase: polymerase chain reaction methods for surveillance in Africa. Am J Trop Med Hyg 1995, 52:565-568.

24. Marks F, von Kalckreuth V, Kobbe R, Adjei S, Adjei O, Horstmann RD, Meyer CG, May J: Parasitological rebound effect and emergence of pyrimethamine resistance in Plasmodium falciparum after single-dose sulfadoxine-pyrimethamine. J Infect Dis 2005, 192:1962-1965.

25. Cisse B, Sokhna C, Boulanger D, Milet J, Bâel H, Richardson K, Hallett R, Sutherland C, Simondon K, Simondon F, Alexander N, Gaye O, Targett G, Lines J, Greenwood B, Trape JF: Seasonal intermittent preventive treatment with artesunate and sulfadoxine-pyrimethamine for prevention of malaria in Senegalese children: a randomised, placebocontrolled, double-blind trial. Lancet 2006, 367:659-667.

26. Dicko A, Sagara I, Sissoko MS, Guindo O, Diallo Al, Kone M, Touré OB, Sacko M, Doumbo OK: Impact of intermittent preventive treatment with sulphadoxine-pyrimethamine targeting the transmission season on the incidence of clinical malaria in children in Mali. Malar J 2008, 7:123.

27. Noranate N, Durand R, Tall A, Marrama L, Spiegel A, Sokhna C, Pradines B, Cojean S, Guillotte M, Bischoff E, Ekala MT, Bouchier C, Fandeur T, Ariey F, Patarapotikul J, Le Bras J, Trape JF, Rogier C, Mercereau-Puijalon O: Rapid dissemination of Plasmodium falciparum drug resistance despite strictly controlled antimalarial use. PLOS ONE 2007, 2:e139.

28. Bogreau H, Renaud F, Bouchiba H, Durand P, Assi SB, Henry MC, Garnotel E, Pradines B, Fusai T, Wade B, Adehossi E, Parola P, Kamil MA, Puijalon O, Rogier C: Genetic diversity and structure of African Plasmodium falciparum populations in urban and rural areas. Am J Trop Med Hyg 2006, 74:953-959.

29. Djimdé AA, Fofana B, Sagara I, Sidibe B, Toure S, Dembele D, Dama S, Ouologuem D, Dicko A, Doumbo OK: Efficacy, safety, and selection of molecular markers of drug resistance by two ACTs in Mali. Am J Trop Med Hyg 2008, 78:455-461.

30. Tekete $M$, Djimdé $A A$, Beavogui $A H$, Maiga $H$, Sagara I, Fofana $B$, Ouologuem D, Dama S, Kone A, Dembele D, Wele M, Dicko A, Doumbo OK: Efficacy of chloroquine, amodiaquine and sulphadoxinepyrimethamine for the treatment of uncomplicated falciparum malaria: revisiting molecular markers in an area of emerging $A Q$ and $S P$ resistance in Mali. Malar J 2009, 8:34.

31. Tinto $\mathrm{H}$, Ouedraogo JB, Zongo I, Van Overmeir C, Van Marck E, Guiguemdé TR, D'alessandro U: Sulfadoxine-pyrimethamine efficacy and selection of Plasmodium falciparum DHFR mutations in Burkina Faso before its introduction as intermittent preventive treatment for pregnant women. Am J Trop Med Hyg 2007, 76:608-613.

32. Ndiaye D, Daily JP, Sarr O, Ndir O, Gaye O, Mboup S, Roper C, Wirth DF: Defining the origin of Plasmodium falciparum resistant dhfr isolates in Senegal. Acta Trop 2006, 99:106-111.

33. Mockenhaupt FP, Teun BJ, Eggelte TA, Schreiber J, Ehrhardt S, Wassilew N, Otchwemah RN, Sauerwein RW, Bienzle U: Plasmodium falciparum dhfr but not dhps mutations associated with sulphadoxine-pyrimethamine treatment failure and gametocyte carriage in northern Ghana. Trop Med Int Health 2005, 10:901-908.

34. Dokomajilar C, Lankoande ZM, Dorsey G, Zongo I, Ouedraogo JB, Rosenthal PJ: Roles of specific Plasmodium falciparum mutations in resistance to amodiaquine and sulfadoxine-pyrimethamine in Burkina Faso. Am J Trop Med Hyg 2006, 75:162-165.

35. Diallo DA, Sutherland C, Nebie I, Konaté AT, Ord R, Pota H, Roper C, Ilboudo-Sanogo E, Greenwood BM, Cousens SN: Sustained use of insecticide-treated curtains is not associated with greater circulation of drug-resistant malaria parasites, or with higher risk of treatment failure among children with uncomplicated malaria in Burkina Faso. Am J Trop Med Hyg 2007, 76:237-244.

doi:10.1186/1475-2875-9-9

Cite this article as: Dicko et al.: Molecular markers of resistance to sulphadoxine-pyrimethamine one year after implementation of intermittent preventive treatment of malaria in infants in Mali. Malaria Journal 2010 9:9.

\section{Publish with Biomed Central and every scientist can read your work free of charge}

"BioMed Central will be the most significant development for disseminating the results of biomedical research in our lifetime. "

Sir Paul Nurse, Cancer Research UK

Your research papers will be:

- available free of charge to the entire biomedical community

- peer reviewed and published immediately upon acceptance

- cited in PubMed and archived on PubMed Central

- yours - you keep the copyright
BioMedcentral 